\title{
Survey design method - the key component of building the Polish Biobanking Network
}

\author{
Angelika Paluch ${ }^{1,3}\left[\right.$, Anna Chróścicka ${ }^{1,2,3}$ []
}

\author{
${ }^{1}$ Laboratory for Cell Research and Application, Center for Preclinical Research and Technology, \\ Medical University of Warsaw, Poland \\ ${ }^{2}$ Department of Histology and Embryology, Center for Biostructure Research, Medical University of Warsaw, Poland \\ ${ }^{3}$ BBMRI.pl Consortium
}

\begin{abstract}
The Polish Biobanking Network was created to connect Polish biobanks and gain information about their collections, thus facilitating their cooperation both in the national and international area. Based on MIABIS (Minimum Information About Blobank data Sharing) and considering the specificity of the Polish scientific community, two surveys were created. The aim of the first survey was to collect general information about Polish biobanks, e.g. their localization and type of collected material. The second survey was more detailed and concerned the biobank's structure, information about collected material, willingness to share the collected material, implementation of an informatics system. Significant information about Polish biobanks could be obtained through appropriate recognition of the biobank's scope of practice and correctly asked questions. The analysis of collected results could give a full picture of Polish biobanks.
\end{abstract}

Keywords: biobank · biobanking · data - survey · survey design

\section{Citation}

Paluch A, Chróścicka A. Survey design method - the key component of building the Polish Biobanking Network. Eur J Transl Clin Med. 2021;4(1):65-70.

DOI: $10.31373 /$ ejtcm/134676

Anna Chróścicka, Department of Histology and Embryology, Center for Biostructure Research, Medical University of Warsaw, Poland; 


\section{Introduction}

Biobanks are research units that collect biological material of various origin and data connected with it [1-3]. There are different types of biobanks: population, specialized, clinical and mixed. Population biobanks gather material of the chosen population and the conditions that exist in it. Specialized biobanks focus on collecting material related to particular conditions, e.g. oncological, genetic or rare diseases [34]. Clinical biobanks collect material obtained after diagnostics procedures and are often de facto part of pharmaceutical/diagnostic companies conducting clinical trials using novel drugs, research on biomarker detection and validation of various types of tests introduced for in vitro diagnostics. Mixed biobanks are characterized by combining the mission of population-type biobanks with specialized or clinical ones and/or both [5]. The material collected in biobanks is an excellent basis for further research because of its diversity and uniqueness [4, 6-7]. Biobanks are often created at medical universities and research centers. Thanks to this it is possible to increase the collections of these biobanks and thus support the development in science [8].

The process of obtaining biological material is inextricably linked with collecting data related to it [9-10]. An appropriate method for gathering the information connected with collected material is crucial because it can support the research carried out on biobanked material. Data describing biological material usually come from questionnaires that are completed by the donors, doctors and researchers. The method of gathering the collected data affects their usefulness. It is not necessary to store all possible data. Therefore, selection of data that is relevant and possible to collect with the sample, is also crucial. In order to select the proper data collection algorithms, it is important to create a special system that will enable this. The basis of such a system is designing a suitable survey whose aim is to gather the most important data that will complement the uniqueness of the collection stored in the biobanks. It is also critical to ensure adequate security of data storage, e.g. by implementing a properly designed informatics system. There are some guidelines, such as Minimum Information About Blobank data Sharing (MIABIS), which aim is to assist with the development of such questionnaires [2, 11]. The MIABIS describes, among other things, the most important data which should be obtained about biobanks by surveys.

Poland is in the initial stage of building its biobank infrastructure and network [12]. Since 2016 Poland, has been a full member of the European Biobanking and BioMolecular resources Research Infrastructure-European Research Infrastructure Consortium (BBMRI-ERIC) which links biobanks from all over Europe [12-14]. Thanks to the activity of the Biobanking and BioMolecular resources Research Infrastructure Consortium in Poland (BBMRI.pl), the process of creating the Polish Biobanking Network (PBN) has begun. One of the main tasks of the PBN is to facilitate cooperation between biobanks and other research institutions located throughout Poland. Activity of the PBN will make biobanks more visible not only in the country but also abroad. It could spread the cooperation between biobanks and other units - research and/or commercial companies. That could also lead to the acceleration of personalized medicine development [6, 9-10]. To achieve this goal, it is important to obtain information about biobanks and biorepositories existing in Poland, first. Then, collected information should be placed in a special database where it would be available to all interested bodies.

The aim of this work is to show how to design surveys that enable obtaining relevant information about biobanks. Figure 1 summarizes the most important factors which should be taken into account during survey designing.

LAYOUT

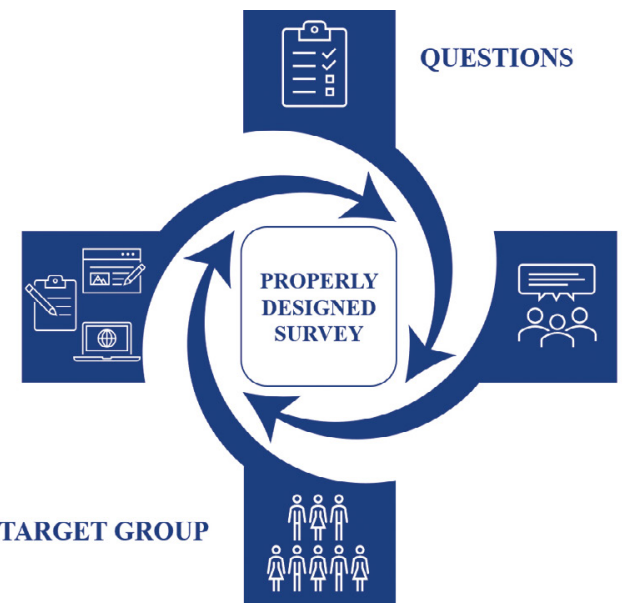

GENERAL COMPOSITION VERIFICATION
Figure 1. Factors which should be taken into account during survey design. The target group - should be clearly defined at first. The layout - cannot be distracting to the respondents. Its main task is to guide the respondent from the first question to the last in a clear and transparent manner. Surveys authors have to decide if it will be in paper or electronic form. The questions - they should be easy to understand, regardless of type (single-choice, multiple-choice, closed, and open-ended). The general format - independent reviewers should verify if the survey is understandable to potential recipients. 
Material and methods

Before starting the process of survey design, it is important to decide what type of information should be obtained from it. The questionnaire should include questions that are closely related to its main purpose. The subject of the questions should be clearly defined [15]. It is important to prioritize the desired responses - authors have to decide which answers are required and which are optional [16].

\section{Who is the target group?}

The survey's aim is to obtain specific information from specific recipients, so it should be designed to suit that target group [17].

\section{Does the layout matter?}

It is necessary to define the layout of the survey, whether it will include only text or will images (or other sources of information) also be included. The purpose of the layout is to clearly and transparently guide the respondent from the first question to the last [18-19]. Therefore, the layout of the survey cannot be distracting to the respondents. In order to provide responses that are valuable to the survey designers, the respondent must see the purpose of completing the survey.

\section{Paper or electronic format?}

Another important aspect that should be considered when designing a survey is its form. Depending on the target group to which the survey is addressed to and regarding its general structure, it is necessary to decide whether the survey should have paper, electronic or both formats. Computer-based surveys are increasingly common. This format is useful when the survey consists of many related questions. The respondents receive only questions tailored to the scope of their biobank work (e.g. after marking that the particular biobank collects samples of human tissues only, then questions about animal tissue samples will not appear in the survey). Thus, the survey becomes clearer and less overwhelming. Online surveys are cheaper, more environmentally friendly and can reach a larger target group in a shorter time.

However, it should be remembered that in some cases classic paper format can also be a good solution. Paper questionnaires are not vulnerable to hackers and reduce the probability of modifying the data selected in them. Some target groups prefer to fill in the paper questionnaire. For example, while waiting for an appointment with their doctor, patients can use that time to complete paper questionnaires.

When deciding on the form of the survey, it is worth considering the analysis of the data obtained from it. Computer-based questionnaires are often connected with software that performs automatic analysis of the collected data. Whereas when choosing the paper format, it should be remembered that the data cannot be analyzed until a human finishes entering it into the chosen database.

The choice of survey format also determines the method of archiving. In case of computer-bassed surveys, this can be a secured server or a cloud service. Considering the paper questionnaires, it should be a place with restricted access, e.g. a dedicated cabinet locked with a key or code. Data collected using surveys can be sensitive, thus every effort should be made to properly secure them regardless of format.

\section{What should the questions look like?}

The questions in the survey should be easy to understand. To achieve this, it is recommended to use short sentences and avoid multiple complex sentences. If the question includes terminology or abbreviations that may be unfamiliar to the respondent, they have to be clearly defined in the text. It is good when questions in questionnaires are related to each other. Thanks to this, respondents who are filling in the questionnaires can be guided by an appropriate path, tailored to their needs.

The survey may include single-choice, multiple-choice, closed and open-ended questions. Single-choice closed questions simplify data analysis and allow assigning respondents to a given group. However, the character of those type of questions limits the responses. The survey authors should strictly select the possible answers, which helps with obtaining precise results. Whereas the multiple-choice closed questions give the respondents the freedom to respond fully. To facilitate this, authors should include an answer choice "other" and in a text field the respondent should be able to enter an answer that has not been suggested by the authors of the survey. Therefore, the open-ended questions reveal the so-called respondent's frame of reference. This type of question is often overlooked by the respondents. It is important to make respondents aware of the purpose of participating in the survey $[18,20]$. Another advantage of the computer-based surveys is that questions regarding information that is particularly valuable to the survey designers can be marked as obligatory and the respondent cannot complete the survey without an- 
swering them. Only the appropriate combination of all these types of questions makes it possible to collect complete and useful answers which fully describe the particular biobank.

\section{Who should verify the format and con- tent of the survey questions?}

The survey should be verified by a person who was not involved in developing it. This person should be familiar with the topics addressed by the survey, however does not have to be a specialist in the given field. Such verification serves to check the legibility of the format and the respondents' understanding of the content.

\section{Results}

To create a database of information describing Polish biobanks, two surveys were designed: Informational and Detailed. The purpose of these surveys was to collect particular information about research units involved in the biobanking of biological material. Both surveys were developed based on the authors' prior experience, other questionnaires and guidelines such as MIABIS. The target group were research centers, universities, clinical centers, private companies and other biobanking-related units located in Poland. Each of the questionnaires contained related single-choice, multiple-choice and open-ended questions.

Both surveys are available in electronic form on a dedicated platform [https://ankietypsb.wum.edu.pl/] Before completing the questionnaires, participants went through a verification process. The data collected from both surveys were stored in a computer system with limited access, thus protecting the survey respondents and authors from unwanted email (spam).

The Informational Survey consists of 39 questions. Its main task was to obtain general information about Polish biobanks. This survey made it possible to start the process of identifying biobanks existing in Poland and describing their collections. The survey consists of questions about biobank localization, its type, its parent entity (if applicable), information describing the biobank's collections (the species the material comes from, the general type of gathered material, the size of collections and storage methods), the quality management and informatic systems. The Informational Survey also included the question of whether a given entity is interested in possible participation/accession to the PBN. Only those units that expressed their willingness to cooperate and consequently joined the PBN were invited to complete the Detailed Survey.
The Detailed Survey consists of 57 questions and is divided into five parts: biobank and its structure, collected material (including information about the samples and their donors, the type of research conducted, ethical issues), sharing biological material (including willing to cooperate with national or international research or commercial companies), informatic system and final questions (general questions asking for i.a. determinig respondent's attitude towards biobanking, trainings and PBN). This questionnaire is a continuation of the Informational Survey and aims to determine the status of identified biobanks and the characteristics of their activities in the context of compliance with BBMRI standards. Although the Detailed Survey is a continuation of the Informational Survey and its questions concern similar topics, it collected more comprehensive information about Polish biobanks and broadened the knowledge about them.

\section{Discussion}

Surveys are one of the most common tools for data collection [19]. Through proper recognition of the biobanking topic and the correct questions' design, it is possible to obtain relevant and reliable information about biobanks and biorepositories. Thanks to the Information and Detailed Surveys it is possible to obtain information not only about the general characteristics of Polish biobanks but also about problems affecting its development and their need for new solutions. Information obtained thanks surveys confirm the need for establishing international networks and organizations, which could share their experience with emerging entities what was presented also by other researchers [2].

The knowledge about biobanks makes it possible to improve research [4]. That in turn can lead to the development of novel personalized therapies [9, 21]. This is important not only in Poland, where the biobanking society is in an early stage of development, but also in other countries and scientific societies.

It is important because like in Poland, PBN connects entities from the whole country and makes all best to implement within their structure the proper standards. It is needed for maintaining high quality of specimens collected in biobanks. The implementation of at least minimum standards strategies developed by networks make it possible to obtain proper samples access, and reached large-scale, efficient use of human biological samples [11, 22-23]. Such standards can be designed more precisely only if their authors know the recipients' demands, which are defined in surveys.

Conducting surveys designed on the basis of special guidelines, general experience and knowledge 
of properly qualified biobank's employees, allows for obtaining the necessary information which is crucial not only in the process of Polish Biobanking Network creating but also for other scientific environments which start building a biobanking network. Collection information about biobanks using properly-designed surveys has taken place not only in Poland but also in other countries in Europe. Networks like the BBMRI-ERIC provide such activities to gain information about biobanks located throughout Europe [24-26]. That improves the development of not only singular entities but also all biobanking field.

\section{Conclusions}

Through appropriate recognition of the biobank's topic and correctly asked questions, significant and descriptive information about Polish entities could be obtained. Based on the obtained results and their analysis, a full picture of Polish biobanks can be formed. Such activities will contribute to the harmonization of issues related to biobanking.

\section{Acknowledgements}

The project is financed by the Ministry of Science and Higher Education (decision No. DIR/ WK/2017/2018/01-1) as part of Poland's accession to the European Research Infrastructure BBMRI-ERIC.

\section{References}

1. Watson PH, Hewitt RE, Catchpoole DR, Grizzle WE. Biobank: What's in a Name? Biopreserv Biobank. 2019;17(3):204-8. Available from: https://www.ncbi.nlm.nih.gov/pubmed/31188628.

2. Paskal W, Paskal AM, Debski T, Gryziak M, Jaworowski J. Aspects of Modern Biobank Activity - Comprehensive Review. Pathol Oncol Res. 2018;24(4):771-85. Available from: https://www.ncbi.nlm.nih.gov/pubmed/29728978.

3. Commission DGfRalE. Biobanks for Europe - A Challenge for Governance. Luxembourg Publications Office of the European Union2012.

4. Baker M. Biorepositories: Building better biobanks. Nature. 2012;486(7401):141-6. Available from: https://www.ncbi. nlm.nih.gov/pubmed/22678297.

5. Zika E, Paci D, Schulte in den Daumen T, Braun A, Rikkers-Defrasne S, Deschenes M, et al. Biobanks in Europe: Prospects for Harmonisation and Networking. 2010. Available from: http://publications.jrc.ec.europa.eu/repository/handle/ JRC57831.

6. Olson JE, Bielinski SJ, Ryu E, Winkler EM, Takahashi PY, Pathak J, et al. Biobanks and personalized medicine. Clin Genet. 2014;86(1):50-5. Available from: https://www.ncbi.nlm.nih.gov/pubmed/24588254.

7. Kinkorova J, Topolcan O. Biobanks in Horizon 2020: sustainability and attractive perspectives. EPMA J. 2018;9(4):345-53. Available from: https://www.ncbi.nlm.nih.gov/pubmed/30538786.

8. Zika E, Paci D, Braun A, Rijkers-Defrasne S, Deschenes M, Fortier I, et al. A European survey on biobanks: trends and issues. Public Health Genomics. 2011;14(2):96-103. Available from: https://www.ncbi.nlm.nih.gov/pubmed/20395653.

9. Liu A, Pollard K. Biobanking for Personalized Medicine. Adv Exp Med Biol. 2015;864:55-68. Available from: https://www. ncbi.nlm.nih.gov/pubmed/26420613.

10. Coppola L, Cianflone A, Grimaldi AM, Incoronato M, Bevilacqua P, Messina F, et al. Biobanking in health care: evolution and future directions. J Transl Med. 2019;17(1):172. Available from: https://www.ncbi.nlm.nih.gov/pubmed/31118074.

11. Norlin L, Fransson MN, Eriksson M, Merino-Martinez R, Anderberg M, Kurtovic S, et al. A Minimum Data Set for Sharing Biobank Samples, Information, and Data: MIABIS. Biopreserv Biobank. 2012;10(4):343-8. Available from: https://www. ncbi.nlm.nih.gov/pubmed/24849882.

12. Witon M, Strapagiel D, Glenska-Olender J, Chroscicka A, Ferdyn K, Skokowski J, et al. Organization of BBMRI.pl: The Polish Biobanking Network. Biopreserv Biobank. 2017;15(3):264-9. Available from: https://www.ncbi.nlm.nih.gov/pubmed/28103080.

13. Biobanking and BioMolecular resources Research Infrastructure in Poland Website [23.07.2020]. Available from: http:// bbmri.pl/pl/.

14. Biobanking and BioMolecular resources Research Infrastructure-European Research Infrastructure Consortium Website [23.07.2020]. Available from: https://www.bbmri-eric.eu/. 
15. Edwards PJ, Roberts I, Clarke MJ, Diguiseppi C, Wentz R, Kwan I, et al. Methods to increase response to postal and electronic questionnaires. Cochrane Database Syst Rev. 2009(3):MR000008. Available from: https://www.ncbi.nlm.nih.gov/ pubmed/19588449.

16. Jones D, Story D, Clavisi O, Jones R, Peyton P. An introductory guide to survey research in anaesthesia. Anaesth Intensive Care. 2006;34(2):245-53. Available from: https://www.ncbi.nlm.nih.gov/pubmed/16617649.

17. Jones TL, Baxter MA, Khanduja V. A quick guide to survey research. Ann R Coll Surg Engl. 2013;95(1):5-7. Available from: https://www.ncbi.nlm.nih.gov/pubmed/23317709.

18. Boynton PM, Greenhalgh T. Selecting, designing, and developing your questionnaire. BMJ. 2004;328(7451):1312-5. Available from: https://www.ncbi.nlm.nih.gov/pubmed/15166072.

19. Safdar N, Abbo LM, Knobloch MJ, Seo SK. Research Methods in Healthcare Epidemiology: Survey and Qualitative Research. Infect Control Hosp Epidemiol. 2016;37(11):1272-7. Available from: https://www.ncbi.nlm.nih.gov/pubmed/27514583.

20. Artino AR, Jr., La Rochelle JS, Dezee KJ, Gehlbach H. Developing questionnaires for educational research: AMEE Guide No. 87. Med Teach. 2014;36(6):463-74. Available from: https://www.ncbi.nlm.nih.gov/pubmed/24661014.

21. Vidal I, Wildhaber BE, Moehrlen U, Regamey N, Trachsel D, Cholewa D, et al. A Swiss database and biobank to better understand and manage congenital lung anomalies. Swiss Med Wkly. 2019;149:w20081. Available from: https://www. ncbi.nlm.nih.gov/pubmed/31256411.

22. Doucet M, Becker KF, Bjorkman J, Bonnet J, Clement B, Daidone MG, et al. Quality Matters: 2016 Annual Conference of the National Infrastructures for Biobanking. Biopreserv Biobank. 2017;15(3):270-6. Available from: https://www.ncbi. nlm.nih.gov/pubmed/27992240.

23. Del Vecchio SJ, Owens EP, Ellis RJ. Kidney cancer biobanking: considerations for a single institutional biorepository. Transl Androl Urol. 2019;8(Suppl 2):S224-S8. Available from: https://www.ncbi.nlm.nih.gov/pubmed/31236340.

24. Goisauf M, Martin G, Bentzen HB, Budin-Ljosne I, Ursin L, Durnova A, et al. Correction: Data in question: A survey of European biobank professionals on ethical, legal and societal challenges of biobank research. PLoS One. 2019;14(12):e0226149. Available from: https://www.ncbi.nlm.nih.gov/pubmed/31790510.

25. Henderson MK, Goldring K, Simeon-Dubach D. Advancing Professionalization of Biobank Business Operations: A Worldwide Survey. Biopreserv Biobank. 2019;17(1):71-5. Available from: https://www.ncbi.nlm.nih.gov/pubmed/30412417.

26. Brunfeldt $M$, Teare $H$, Soini S, Kaariainen $H$. Perceptions of legislation relating to the sharing of genomic biobank results with donors-a survey of BBMRI-ERIC biobanks. Eur J Hum Genet. 2018;26(3):324-9. Available from: https://www.ncbi. nlm.nih.gov/pubmed/29330544. 